Why Is Mobile Capital Taxed?*

by

Kangoh Lee

Department of Economics

San Diego State University

San Diego, CA 92182-4485

email:klee@mail.sdsu.edu

December 2011

${ }^{*}$ I am grateful to Sam Bucovetsky and John Wilson for their comments on an earlier version of this paper, and I also thank two anonymous referees for their helpful comments that improve the paper significantly. This research was in part supported by a critical thinking (assigned time) grant from the College of Arts and Letters at San Diego State University. 
Abstract The government for a jurisdiction has both capital and labor taxes at its disposal. It taxes mobile capital to finance the public good despite the desire to attract capital and despite the tax on immobile labor if capital incomes are distributed more unequally than labor incomes among the residents of the jurisdiction. The result extends to progressive taxes and to pure redistribution.

JEL classification: H71, H72, H73

Key words: mobile capital; capital tax; labor tax 


\section{Why Is Mobile Capital Taxed?}

\section{Introduction}

As economies have become increasingly more open due to market integration such as the formation of the European Union and its expansion, capital moves more freely among countries and competition for mobile capital has intensified. Accordingly, researchers and policymakers both have paid a good deal of attention to the effects of market integration. In particular, they have expressed a concern that attempts of jurisdictions to attract capital lower the taxes on capital and lead to underprovision of the public goods (OECD 1998, 2000; Wilson and Wildasin 2004). In addition, tax competition models suggest that the tax on mobile capital is distortionary and that mobile capital should not be taxed if immobile factors can be taxed (Zodrow and Mieszkowski 1986; Wildasin 1989). While the concern is a logical consequence of the standard model of tax competition, it does not seem to be consistent with reality, as the effective capital tax rates for European Union countries range from $11.1 \%$ in Ireland to $53.1 \%$ in Sweden (Haufler 2001) and the average effective capital tax rate for OECD countries is $31.5 \%$ (Chen et al. 2007). The goal of the paper is to consider a more realistic environment that can explain such capital taxes. In particular, the analysis demonstrates the possibility that mobile capital is taxed even though the tax on mobile capital is distortionary and immobile factors can be taxed.

A jurisdiction consists of heterogeneous residents in terms of their factor endowments, and the objective of the jurisdiction is to maximize a Benthamite social welfare function. This gives the jurisdiction the incentive to redistribute from rich to poor residents. The rich own more capital and more labor than the poor. In addition, the rich own relatively more capital than labor while the poor own relatively more labor than capital, or capital incomes are distributed more unequally than labor incomes, as observed in practice (Diaz-Gimenez et al. 1997; Goodman et al. 1997). The government for a jurisdiction has both capital and labor taxes at its disposal to finance the public good. Capital is freely mobile between jurisdictions while labor is of fixed supply and immobile. If immobile labor is taxed, mobile capital is not taxed in the standard model with homogeneous residents, because the tax on mobile capital distorts the allocation of resources while the tax on immobile labor amounts to lump-sum taxation. However, with heterogeneous residents, capital is 
taxed. The reason is that an increase in the capital tax increases the tax revenues and hence the public good but decreases the capital incomes. The jurisdictional welfare gain from the increased public good depends on the distribution of labor endowments as the labor tax is chosen to satisfy a Samuelson-type condition for an optimal level of the public good in a jurisdiction. The jurisdictional welfare cost from the decreased capital income depends on the distribution of capital endowments. If the rich own relatively more capital while the poor own relatively more labor, then the increased public good, resulting from the increase in the capital tax, benefits the poor relatively more while the costs of the decreased capital incomes are borne relatively more by the rich. The jurisdiction that desires to maximize its jurisdictional welfare thus taxes capital despite the well-known distortionary effect of the tax on mobile capital and despite the available tax on immobile labor.

The result that mobile capital is taxed in equilibrium despite the tax on immobile labor extends to progressive labor taxes and to lump-sum redistribution. With progressive labor taxes, a jurisdiction taxes $100 \%$ of the rich's labor incomes although it desires to tax them more, because the tax rate cannot exceed $100 \%$. The taxes and hence the public good level are thus lower than the maximization of the jurisdictional welfare dictates, increasing the marginal benefit from the increased public good. Progressive labor taxes thus increase the jurisdictional welfare gain from the increased public good, caused by an increase in the capital tax, making it more likely that capital is taxed than with a single labor tax rate. If the tax revenues are used to provide the public good and to redistribute income in the form of a lump-sum transfer for all residents of the jurisdiction, it again makes it more likely that capital is taxed. This occurs because the rich pay more capital taxes to finance the transfers while everyone receives the same transfer.

The next section surveys a few strands of related literature that study why mobile capital is taxed in the presence of non-distortionary taxes. Section 3 describes a simple model of capital taxation with heterogeneous residents in terms of factor endowments. Section 4 analyzes the labor and capital taxes chosen by a jurisdiction, and Section 5 discusses inefficiency of capital taxation. Section 6 extends the analysis to progressive labor taxes and to lump-sum redistribution. The last section concludes.

\section{Related Literature}


The question of why mobile capital is taxed in the presence of non-distortionary taxes is related to a number of strands of literature. ${ }^{1}$ First, even though labor or profit taxes are available, mobile capital may be taxed due to labor market imperfections. Richter and Schneider (2001) consider a monopsony model of labor market, and demonstrate that it is beneficial to tax capital if profit income cannot be taxed although wage income is taxable. In a model of dual labor markets with competitive and unionized sectors, Koskela and Schöb (2005) show that taxing capital is efficient despite non-distortionary profit taxes, as it reduces the competitive wage that serves as an outside option for unionized workers, increasing employment and output in the unionized sector. Ogawa et al. (2006) study tax competition with unemployment, and argue that a jurisdiction taxes capital even with a head tax, because capital taxation decreases the amount of capital and increases employment in the jurisdiction when capital and employment are substitutes.

Second, recognizing that free mobility of capital is not optimal when foreign-source incomes cannot be taxed, jurisdictions impose capital controls. In such models with capital controls, it may be efficient to tax mobile capital. The reason is that capital controls by a jurisdiction increase, relative to free mobility of capital, the amount of capital and hence the capital tax base in the jurisdiction, enabling the jurisdiction to lower the capital tax rate to achieve the same tax revenues (Razin and Sadka 1991). Huber (1997) considers transactions costs of making international financial transactions, and shows that whether capital is taxed depends on the revenue requirement of a jurisdiction. In particular, when the requirement is high, jurisdictions both tax capital and impose capital controls.

Third, when firms in a jurisdiction are partly owned by foreigners, the jurisdiction has an incentive to tax profits earned by foreigners. Since profits depend on capital, capital taxation serves as an instrument to tax profits. Jurisdictions thus tax capital to capture part of profits earned by foreigners, as in Huizinga and Nielsen (1997) and Sörensen (2004). In Burbidge et al. (2006), firms move in response to the difference in profit taxes between jurisdictions, and profit taxes are distortionary. Nevertheless, the governments of jurisdictions impose a tax on profits in order to collect part of profits that accrue to foreigners even if non-distortionary labor taxes are available.

Fourth, Huber (1999) considers an optimum labor and capital income tax problem in a tax

\footnotetext{
${ }^{1}$ Most of the papers examine the possibility of taxing or subsidizing capital, like in this paper, but the discussion below focuses on taxation to conserve space.
} 
competition model with unobservable wages or abilities. An increase in the capital tax of a jurisdiction decreases capital, altering the wages of both high-skilled and low-skilled individuals and hence affecting the self-selection constraint. Since the social-welfare maximizing government wishes to weaken the self-selection constraint, it taxes capital if the outflow of capital due to the capital tax lowers the ratio of the high-skilled individual's wage to the low-skilled individual's wage while it subsidizes capital otherwise. Fuest and Huber (2001) analyze a similar model with a lump-sum tax, and find that capital is subsidized in order to weaken the self-selection constraint.

Fifth, as in this paper, heterogeneous factor ownership may be a reason for capital taxation. In Braulke and Corneo (2004), an increase in the capital tax of a country (i) lowers the wage incomes of the country due to the exodus of capital, (ii) increases the capital tax revenues, and (iii) decreases the capital incomes, net of the taxes, (income from capital owned by the country's citizens). Effect (ii) outweighs effect (i), because a 1 dollar increase in the tax increases the tax revenues by the same 1 dollar per unit of capital, but it decreases the wage incomes less than 1 dollar. $^{2}$ In addition, the more capital is located in the country or equivalently the more labor the country has, the more tax revenues it collects from the increase in the tax. ${ }^{3}$ At the same time, the loss of capital income by the country decreases if their citizens own less capital. As a result, the country benefits from capital taxation and will tax mobile capital when the country has more labor and less capital relative to other countries. In this paper, countries are identical, and there is no world-wide redistribution between countries. Rather, redistribution occurs among the citizens of a country. Borck (2003) considers a voting equilibrium on labor and capital taxes with tax competition. If the median voter owns less capital and more labor than the average of a jurisdiction, he prefers to tax mobile capital even though immobile labor can be taxed. The reason is that for the median voter, the income loss resulting from capital taxation is less than the average while the gain from the increased public good depends on the average tax base or the average amount of capital. That is, the median voter of a jurisdiction prefers to tax capital, because capital taxation redistributes to himself from the rest of the jurisdiction. This median voter's desire to redistribute to himself is analogous to that in Meltzer

\footnotetext{
${ }^{2}$ The return to capital equals $f^{\prime}(k)=r$ (interest) $+\tau$ (capital tax), and total differentiation gives $f^{\prime \prime}(k)(\partial k / \partial \tau)=$ $1+\partial r / \partial \tau<1$. The change in the wage incomes equals $\partial\left(f-k f^{\prime}\right) / \partial \tau=-k f^{\prime \prime}(\partial k / \partial t)>-k$ while the change in the tax revenue equals $k$.

${ }^{3}$ Due to perfectly mobile capital and identical production functions, the capital-labor ratio is identical across countries, meaning that more capital of a country means a more labor of the country.
} 
and Richard (1981). This paper takes a jurisdictional welfare approach, and whether a jurisdiction prefers to tax capital depends on the distribution of factor endowments among the residents of the jurisdiction. As a result, the condition for capital taxation in this paper differs from that in Borck (2003), as will be discussed in Section4-B. ${ }^{4}$

\section{The Model}

The economy consists of $q$ jurisdictions, and jurisdiction $i$ has $n_{i}$ residents, $i=1,2, \ldots, q$. The residents of jurisdiction $i$ differ only in their factor endowments, capital and labor, where labor is measured in effective units. ${ }^{5}$ Resident $h$ of jurisdiction $i$ owns a fraction $\alpha_{i h} \in[0,1]$ of the jurisdiction's exogenous capital stock $\bar{k}_{i}$, and a fraction $\beta_{i h} \in[0,1]$ of the jurisdiction's exogenous total labor supply $\bar{\ell}_{i}$, with

$$
\sum_{h=1}^{n_{i}} \alpha_{i h}=1, \text { and } \sum_{h=1}^{n_{i}} \beta_{i h}=1, \text { for } i=1,2, \ldots, q .
$$

Assume

$$
\alpha_{i h^{\prime}}>\alpha_{i h}, \text { and } \beta_{i h^{\prime}}>\beta_{i h}, \text { for } h^{\prime}>h, h=1,2, \ldots, n_{i}-1
$$

The inequalities say that resident $h^{\prime}$ of jurisdiction $i$ owns more capital and more labor than resident $h$, and that resident $h^{\prime}$ is richer than resident $h$. This assumption is much stronger than needed but simplifies the presentation, as discussed below. Nevertheless, this assumption does not seem unreasonable, because there appears to be a positive correlation between income from capital and income from labor (resident $h^{\prime}$ earns more income from capital and more income from labor than resident $h$ does). That is, high wage earners can save and invest more, leading to more income from capital. This explains a positive correlation. To see the other direction that higher income from capital means higher income from labor, note that those families with higher capital income can better afford education for their children (Loury 1981; Banerjee and Newman 1993; Galor and Zeira 1993), ${ }^{6}$ and those children with more education can earn higher wages (Card and Krueger 1992;

\footnotetext{
${ }^{4}$ Lee (2004) explores another reason for capital taxation in a model with production uncertainty. An increase in the capital tax drives capital out of the jurisdiction and hence moderates the fluctuation of the uncertain wages due to complementarity between labor and capital. As a result, the distortionary tax on mobile capital acts as insurance and capital is taxed even though a lump-sum tax is available. This result is analogous to that in Eaton and Rosen (1980a, 1980b).

${ }^{5}$ Labor endowments thus differ across individuals. In particular, individuals supply the same quantity of labor inelastically, but they differ in their productivity so that the number of effective units of labor supply differs, as in human capital theory.

${ }^{6}$ Liquidity constraints that low income families face limit their ability to provide education for their children, and those children with less education earn lower wages (Card and Krueger 1992; Murnane et al. 1995).
} 
Murnane et al. 1995). In addition to these arguments, using a set of U. S. data from the 1992 Survey of Consumer Finances and the 1984-5 and 1989-0 Panel Study of Income Dynamics, Diaz-Gimenez et al. (1997) finds that there is a positive correlation between wealth and labor earnings in the United States.

Employing capital $k_{i}$ and labor $\ell_{i}$, each jurisdiction produces a single output that serves as a numeraire according to a constant-returns-to-scale technology, $f_{i}\left(k_{i}, \ell_{i}\right)$. The government for jurisdiction $i$ imposes a source-based proportional tax on the returns to capital (capital incomes), $t_{i} \leq 1$, and a proportional tax on the returns to labor (labor incomes), $\tau_{i} \leq 1$, employed in its jurisdiction to finance the public good, $z_{i}$, and/or lump-sum transfers (redistribution) $T_{i}$.

Capital is perfectly mobile between jurisdictions, and the employment of capital in each jurisdiction, $k_{i}$, is endogenously determined by the tax policies of jurisdictions, $\left(t_{1}, t_{2}, \ldots, t_{q}\right)$. The net returns to capital must then be equalized, and

$$
\left(1-t_{i}\right) f_{i}^{\prime}\left(k_{i}\right)=\rho, i=1,2, \ldots, q
$$

where $\rho$ is the economy-wide net return to capital. The total capital supply to the economy is fixed at $\sum_{i=1}^{q} \bar{k}_{i}$, so that

$$
\sum_{i=1}^{q} k_{i}=\sum_{i=1}^{q} \bar{k}_{i} .
$$

Labor is assumed immobile, and $\ell_{i}=\bar{\ell}_{i}$, so $\ell_{i}=\bar{\ell}_{i}$ is omitted in the production function $f_{i}\left(k_{i}\right)$. The $q$ equations in (3), along with (4), implicitly determine the $q+1$ endogenous variables, $\left(k_{1}, k_{2}, \ldots, k_{q}, \rho\right)$, given the tax policies of $q$ jurisdictions, $\left(t_{1}, t_{2}, \ldots, t_{q}\right)$. Total differentiation of the $q+1$ conditions in (3) and (4) can $\operatorname{show}^{7}$

$$
\begin{gathered}
\frac{\partial k_{i}(.)}{\partial t_{i}}=\frac{f_{i}^{\prime}}{D\left(1-t_{i}\right) f_{i}^{\prime \prime}} \sum_{j \neq i} \frac{1}{\left(1-t_{j}\right) f_{j}^{\prime \prime}}<0, \\
\frac{\partial k_{i}(.)}{\partial t_{j}}=-\frac{1}{D\left(1-t_{i}\right) f_{i}^{\prime \prime}} \frac{f_{j}^{\prime}}{\left(1-t_{j}\right) f_{j}^{\prime \prime}}>0, \\
\frac{\partial \rho}{\partial t_{i}}=-\frac{1}{D} \frac{f_{i}^{\prime}}{\left(1-t_{i}\right) f_{i}^{\prime \prime}}<0, D \equiv \sum_{j=1}^{q} \frac{1}{\left(1-t_{j}\right) f_{j}^{\prime \prime}}<0, i \neq j, i, j=1,2, \ldots, q,
\end{gathered}
$$

\footnotetext{
${ }^{7}$ Total differentiation of $\left(1-t_{i}\right) f_{i}^{\prime}=\rho$ with respect to $t_{i}$ gives $\partial k_{i} / \partial t_{i}=\left(f_{i}^{\prime}+\partial \rho / \partial t_{i}\right) /\left(1-t_{i}\right) f_{i}^{\prime \prime}$ while total differentiation of $\left(1-t_{j}\right) f_{j}^{\prime}=\rho$ with respect to $t_{i}$ gives $\partial k_{j} / \partial t_{i}=\left(\partial \rho / \partial t_{i}\right) /\left(1-t_{j}\right) f_{j}^{\prime \prime}, j \neq i$. Total differentiation of (4) with respect to $t_{i}$, along with the expressions for $\partial k_{i} / \partial t_{i}$ and $\partial k_{j} / \partial t_{i}$, gives the desired results in (5).
} 
where the arguments of the production functions are omitted for simplicity. Intuitively, an increase in $t_{i}$ lowers the net return to capital employed in jurisdiction $i$, driving capital out of jurisdiction $i$. An increase in $t_{j}$ drives capital from jurisdiction $j$, increasing $k_{i}$. An increase in the tax of a jurisdiction decreases the net return to capital. As indicated in (5), the analysis assumes that a jurisdiction's tax policy affects the net return to capital, $\partial \rho / \partial t_{i}<0$, so that the jurisdiction can alter the capital incomes of its residents and hence its jurisdictional welfare. If $\partial \rho / \partial t_{i}=0$, as is the case with infinitely many jurisdictions, then a jurisdiction of course would have no incentive to tax capital, as in Bucovetsky and Wilson (1991).

Factor markets are competitive, and each factor earns its marginal product. A unit of capital in jurisdiction $i$ earns the gross return $f_{i}^{\prime}\left(k_{i}\right)$, and the net return $\rho$. A unit of labor earns the gross return $\left[f_{i}\left(k_{i}\right)-k_{i} f_{i}^{\prime}\left(k_{i}\right)\right] / \bar{\ell}_{i}$, and the net return equals $\left(1-\tau_{i}\right)$ times the gross return. Given the factor endowments described above, resident $h$ of jurisdiction $i$ earns the income net of taxes,

$$
x_{i h}=\alpha_{i h} \bar{k}_{i} \rho+\beta_{i h}\left(1-\tau_{i}\right)\left[f_{i}\left(k_{i}\right)-k_{i} f_{i}^{\prime}\left(k_{i}\right)\right], h=1,2, \ldots, n_{i}, \text { and } i=1,2, \ldots ., q .
$$

The first term of the equation shows the capital income net of taxes, and the remaining terms represent the net labor income. The tax revenues of jurisdiction $i$ equal

$$
R_{i}=t_{i} k_{i} f_{i}^{\prime}+\tau_{i}\left(f_{i}-k_{i} f_{i}^{\prime}\right)
$$

The tax revenues are used to provide the public good $z_{i}$. Assuming for simplicity that one unit of the private good can be transformed into one unit of the public good,

$$
z_{i}=R_{i}
$$

In (6) through (8), a lump-sum transfer $T_{i}$ was not considered, but Section 6-B will consider it. The residents of jurisdiction $i$ have the same preferences, represented by a concave utility function $U_{i}\left(x_{i h}, z_{i}\right)$.

In studying the characteristics of the capital taxes that the governments for jurisdictions choose, much of the tax competition literature has focused on the case with homogeneous residents of a jurisdiction, and the benevolent government is assumed to maximize the utility of a representative resident. In the current setup, a jurisdiction consists of heterogeneous residents, and the government needs to aggregate the heterogeneous preferences when selecting the taxes. This paper assumes 
that the benevolent government for a jurisdiction maximizes the sum of the utilities of residents. In particular, the government is assumed to maximize a utilitarian jurisdictional welfare function, $V_{i} \equiv \sum_{h=1}^{n_{i}} U_{i}\left(x_{i h}, z_{i}\right){ }^{8}$ Since $k_{i}$ enters the utilities of the residents of jurisdiction $i$, and since $k_{i}$ depends on the tax policies of all jurisdictions, $\left(t_{1}, t_{2}, \ldots, t_{i}, \ldots, t_{q}\right)$, the tax policies are jointly determined. A Nash equilibrium in the tax rates is considered for the subsequent analysis.

The maximization of jurisdictional welfare is usually considered a normative approach. At the same time, a normative approach in the tax competition literature typically examines the determination of capital taxes from the economy's (all jurisdictions) perspective, rather than from a single-jurisdiction's perspective. Indeed, Section 5 considers efficiency of tax competition, a normative question, and shows that tax competition results in inefficiency associated with the mobility of capital between jurisdictions. For this reason, the maximization of jurisdictional welfare within a jurisdiction is called a positive approach that helps in aggregating heterogeneous preferences. The jurisdictional welfare approach, taken in this paper, is consistent with and comparable to the standard models of tax competition that focus on identical residents in a jurisdiction, in the sense that there is no inefficiency from a jurisdiction's perspective but there is from the economy's perspective. As mentioned in the previous section, an alternative positive approach is to consider majority voting on taxes, and the difference between two approaches will be discussed in Section 4-B. Another positive approach is to assume that taxes are determined by lobbying activities, and welfare maximization here may be interpreted as a closed-form solution to a lobbying game, such as the one in Grossman and and Helpman (1994). In particular, Grossman and Helpman (1994) show that the equilibrium of the lobbying game may coincide with the efficient solution that maximizes social welfare. ${ }^{9}$

For the analysis of tax competition to be meaningful, a Nash equilibrium in the tax rates must exist. However, it has been known to be notoriously difficult to establish the existence. The difficulty is that even if the utility function $U_{i}\left(x_{i h}, z_{i}\right)$ is concave in $x_{i h}$ and $z_{i}$ and the production function $f_{i}\left(k_{i}\right)$ is concave, the utility function is not necessarily quasi-concave in the tax rates due to

\footnotetext{
${ }^{8}$ Section 4-B considers other objectives.

${ }^{9}$ Grossman and Helpman (1994) postulate that the government or a politician chooses a policy to maximize the sum of political contributions and social welfare, given the contribution schedules determined by the lobbies. Since the politician desires to receive political contributions, the policy in a political equilibrium is not necessarily set to maximize social welfare. However, they show that the equilibrium policy maximizes social welfare and hence is efficient when all voters are represented by lobbying groups. This paper does not argue that the equilibrium of the lobbying game is efficient. Rather, the efficient equilibrium makes the analysis consistent with the tax competition literature, as it makes the policy efficient within a jurisdiction.
} 
the presence of $\partial k_{i} / \partial t_{i}$ in (5). A few attempts have been made to establish the existence of a Nash equilibrium (Bucovetsky 1991; Laussel and Le Breton 1998; Bayindir-Upmann and Ziad 2005), but the conditions for the existence in these studies appear to be demanding, indicating the difficulty of proving the existence more generally. For these reasons, it has been standard to not discuss the existence issue in the tax competition literature, and this paper assumes the existence of a Nash equilibrium. ${ }^{10}$

\section{Basic Analysis}

\section{4-A Capital Taxes}

The government for jurisdiction $i$ chooses $\tau_{i}$ and $t_{i}$, taking $\tau_{j}$ and $t_{j}$ as given, in order to maximize $V_{i} \equiv \sum_{h=1}^{n_{i}} U_{i}\left(x_{i h}, z_{i}\right)$. The first-order conditions for an interior maximum of $V_{i}$ read as

$$
\begin{gathered}
\frac{d V_{i}}{d \tau_{i}}=\left(f_{i}-k_{i} f_{i}^{\prime}\right) \sum_{h=1}^{n_{i}}\left[U_{i h}^{z}-U_{i h}^{x} \beta_{i h}\right]=0 \Longrightarrow \sum_{h=1}^{n_{i}} U_{i h}^{z}=\sum_{h=1}^{n_{i}} U_{i h}^{x} \beta_{i h}, \\
\frac{d V_{i}}{d t_{i}}=\sum_{h=1}^{n_{i}}\left[U_{i h}^{x}\left(\alpha_{i h} \bar{k}_{i} \frac{\partial \rho}{\partial t_{i}}-\left(1-\tau_{i}\right) \beta_{i h} k_{i} f_{i}^{\prime \prime} \frac{\partial k_{i}}{\partial t_{i}}\right)+U_{i h}^{z}\left(k_{i} f_{i}^{\prime}+\left(t_{i} f_{i}^{\prime}+t_{i} k_{i} f_{i}^{\prime \prime}-\tau_{i} k_{i} f_{i}^{\prime \prime}\right) \frac{\partial k_{i}}{\partial t_{i}}\right)\right]=0,
\end{gathered}
$$

where superscripts $x$ and $z$ in the utility functions denote partial derivatives such as $U_{i h}^{x} \equiv \partial U_{i}\left(x_{i h}, z_{i}\right) / \partial x_{i h}$, and the arguments of the utility functions are omitted for simplicity. The first condition of (9), $\sum_{h=1}^{n_{i}} U_{i h}^{z}=\sum_{h=1}^{n_{i}} U_{i h}^{x} \beta_{i h}$, is a Samuelson-type condition for an optimal level of the public good $z_{i}$, associated with the use of a labor tax and with the Benthamite welfare objective.

As the question concerns the possibility of taxing capital despite the taxes on the immobile factor, it suffices to evaluate the sign of $d V_{i} / d t_{i}$ at $t_{i}=0$, which equals

$$
\begin{gathered}
\left.\frac{d V_{i}}{d t_{i}}\right|_{\left(t_{i}=0\right)}=\sum_{h=1}^{n_{i}}\left[U_{i h}^{x}\left(\alpha_{i h} \bar{k}_{i} \frac{\partial \rho}{\partial t_{i}}-\left(1-\tau_{i}\right) \beta_{i h} k_{i} f_{i}^{\prime \prime} \frac{\partial k_{i}}{\partial t_{i}}\right)+U_{i h}^{z}\left(k_{i} f_{i}^{\prime}-\tau_{i} k_{i} f_{i}^{\prime \prime} \frac{\partial k_{i}}{\partial t_{i}}\right)\right] \\
=\sum_{h=1}^{n_{i}}\left[U_{i h}^{x}\left(\alpha_{i h} \bar{k}_{i} \frac{\partial \rho}{\partial t_{i}}-\left(1-\tau_{i}\right) \beta_{i h} k_{i} f_{i}^{\prime \prime} \frac{\partial k_{i}}{\partial t_{i}}\right)+U_{i h}^{x} \beta_{i h}\left(k_{i} f_{i}^{\prime}-\tau_{i} k_{i} f_{i}^{\prime \prime} \frac{\partial k_{i}}{\partial t_{i}}\right)\right] \\
=\sum_{h=1}^{n_{i}} U_{i h}^{x}\left[\alpha_{i h} \bar{k}_{i} \frac{\partial \rho}{\partial t_{i}}+\beta_{i h}\left(k_{i} f_{i}^{\prime}-k_{i} f_{i}^{\prime \prime} \frac{\partial k_{i}}{\partial t_{i}}\right)\right] \\
=\sum_{h=1}^{n_{i}} U_{i h}^{x}\left[-\alpha_{i h} \bar{k}_{i} f_{i}^{\prime} \frac{1}{D f_{i}^{\prime \prime}}+\beta_{i h} k_{i} f_{i}^{\prime} \frac{1}{D f_{i}^{\prime \prime}}\right]
\end{gathered}
$$

\footnotetext{
${ }^{10}$ It is possible to establish the existence of a Nash equilibrium without relying on the quasi-concavity of the payoff function (Vives 2001, Ch. 2). However, this issue is beyond the scope of this paper.
} 


$$
=\frac{f_{i}^{\prime}}{D f_{i}^{\prime \prime}} \sum_{h=1}^{n_{i}} U_{i h}^{x}\left[\beta_{i h} k_{i}-\alpha_{i h} \bar{k}_{i}\right]
$$

The second equality uses the Samuelson-type condition, $\sum_{h=1}^{n_{i}} U_{i h}^{z}=\sum_{h=1}^{n_{i}} U_{i h}^{x} \beta_{i h}$, in (9). ${ }^{11}$ The fourth equality comes from (5). The sign of (10) depends on the relationship between $k_{i}$ and $\bar{k}_{i}$, and on the relationship between $\alpha_{i h}$ and $\beta_{i h}$. To see the first relationship, consider the case of identical residents in the standard models with $\alpha_{i h}=\beta_{i h}=1 / n_{i}$ and $x_{i h}=x_{i}$ for all $h$. Eq. (10) then reduces to $\left(f_{i}^{\prime} / D f_{i}^{\prime \prime}\right) U_{i}^{x}\left(k_{i}-\bar{k}_{i}\right)$, whose sign is the same as the sign of $k_{i}-\bar{k}_{i}$. The last expression can be considered a terms-of-trade effect. If $k_{i}>\bar{k}_{i},(10)$ becomes positive and $t_{i}^{*}>0$ with $*$ denoting an equilibrium. Intuitively, in this case, jurisdiction $i$ employs capital more than its endowments by importing capital. As a consequence, an increase in $t_{i}$ benefits jurisdiction $i$, as the increase in $t_{i}$ lowers the net return to capital that jurisdiction $i$ pays when importing capital. Jurisdiction $i$ thus taxes capital. If $k_{i}<\bar{k}_{i}$, the opposite holds and jurisdiction $i$ subsidizes capital. As the paper focuses on the effect of heterogeneity in factor endowments of residents on capital taxes, this terms-of-trade effect will be ignored to sharpen the result. To that end, jurisdictions are assumed identical for the subsequent analysis. The analysis of identical jurisdictions has been much of the focus of the literature. ${ }^{12}$ More importantly, this paper concerns the effects of the heterogeneity of residents in terms of factor endowments within a jurisdiction, and the assumption of identical jurisdictions helps in isolating the effects of the heterogeneity of residents in a clear manner.

With the identical-jurisdiction assumption, (10) becomes

$$
\left.\frac{d V_{i}}{d t_{i}}\right|_{\left(t_{i}=0\right)}=\frac{f_{i}^{\prime}}{D f_{i}^{\prime \prime}} k \sum_{h=1}^{n_{i}} U_{i h}^{x}\left(\beta_{i h}-\alpha_{i h}\right),
$$

where $k \equiv k_{i}=\bar{k}_{i}$. Assume that income from capital is more unequally distributed than income from labor, so that there is a critical resident, called resident $\hat{h} \in\left(1, n_{i}\right)$, and

$$
\delta_{i h} \equiv \alpha_{i h}-\beta_{i h}<(=,>) 0 \text { for } h<(=,>) \hat{h}, h=1,2, \ldots, n_{i} \text {. }
$$

The assumption states that the poor with $h<\hat{h}$ own more labor than capital while the rich with $h>\hat{h}$ own more capital than labor. ${ }^{13}$ Observe that assumption (12) does not require that $\delta_{i h^{\prime}}>\delta_{i h}$

\footnotetext{
${ }^{11}$ Due to the Samuelson-type condition, the terms involving the labor tax rate, $\tau_{i} \beta_{i h} k_{i} f_{i}^{\prime \prime}\left(\partial k_{i} / \partial t_{i}\right)$, vanish, as in the third equality.

${ }^{12}$ For the analysis of non-identical jurisdictions, see for example Wilson (1991) and Brueckner (2000).

${ }^{13}$ Recalling that $\alpha$ and $\beta$ are fractions, the poor own more labor than capital in terms of their fractions of the total labor income and the total capital income of the jurisdiction, but not necessarily in terms of dollar amounts of their labor income and their capital income. An analogous comment applies to the rich.
} 
for $h^{\prime}>h$. That is, it is possible, for example, that $\delta_{i 1}<\delta_{i 3}<\delta_{i 2}<\ldots<\delta_{i \hat{h}}=0<\ldots$, so that resident 2 , poorer than resident 3 , can own 'relatively' more capital than resident 3 although both residents are poor (their $\delta$ 's are negative) and hence own more labor than capital. That is, all it says is that the poor with $h<h^{\prime}$ have more labor than capital and their $\delta$ 's are negative, but their rankings in terms of $\delta$ do not matter among the poor. Likewise, the rich with $h>h^{\prime}$ have more capital than labor and their $\delta$ 's are positive, but their rankings do not matter among the rich. ${ }^{14}$ By contrast, if income from labor is more unequally distributed than income from capital, the inequalities in (12) are reversed, so that

$$
\delta_{i h} \equiv \alpha_{i h}-\beta_{i h}>(=,<) 0 \text { for } h<(=,>) \hat{h}, h=1,2, \ldots, n_{i} .
$$

If (12) holds, the sign of (11) is positive, because $\mathrm{b}^{15}$

$$
\begin{gathered}
\sum_{h=1}^{n_{i}} U_{i h}^{x}\left(\beta_{i h}-\alpha_{i h}\right)=\sum_{h=1}^{n_{i}} U_{i h}^{x}\left[-\delta_{i h}\right] \\
=\sum_{h=1}^{\hat{h}} U_{i h}^{x}\left[-\delta_{i h}\right]+\sum_{\hat{h}}^{n_{i}} U_{i h}^{x}\left[-\delta_{i h}\right] \\
>U_{i \hat{h}}^{x} \sum_{h=1}^{\hat{h}}\left[-\delta_{i h}\right]+U_{i \hat{h}}^{x} \sum_{\hat{h}}^{n_{i}}\left[-\delta_{i h}\right] \\
=U_{i \hat{h}}^{x} \sum_{h=1}^{n_{i}}\left[-\delta_{i h}\right]=0 .
\end{gathered}
$$

The inequality follows because $\left[-\delta_{i h}\right]>0$ and $U_{i h}^{x}>U_{i \hat{h}}^{x}$ for all $h<\hat{h}$, and because $\left[-\delta_{i h}\right]<0$ and $U_{i h}^{x}<U_{i \hat{h}}^{x}$ for all $h>\hat{h}$. The last equality uses (1), $\sum_{h=1}^{n_{i}}\left[-\delta_{i h}\right]=\sum_{h=1}^{n_{i}}\left(\beta_{i h}-\alpha_{i h}\right)=0$. Intuitively, since $\left[-\delta_{i h}\right]>0$ for the poor while $\left[-\delta_{i h}\right]<0$ for the rich, and since the poor's marginal utility of private good consumption, $U_{i h}^{x}$, carries more weight than the rich's due to the concavity of $U_{i}($.$) , the$ poor's positive values of $U_{i h}^{x}\left[-\delta_{i h}\right]$ outweigh the rich's negative values of $U_{i h}^{x}\left[-\delta_{i h}\right] .{ }^{16}$ As a result, $\sum_{h=1}^{n_{i}} U_{i h}^{x}\left[-\delta_{i h}\right]>0$, and $t_{i}^{*}>0$. If (13) holds, the inequality in (14) is reversed, and $t_{i}^{*}<0$ and

\footnotetext{
${ }^{14}$ The poor (the rich) are used as a relative concept and not specified throughout whenever their identity is clear.

${ }^{15} \hat{h}$ is assumed an integer. If not, take the largest integer smaller than $\hat{h}$ (denoted $h-$ ) and the smallest integer greater than $\hat{h}$ (denoted $h+$ ), and write the summation in (14) as $\sum_{h=1}^{n_{i}}=\sum_{h=1}^{h-}+\sum_{h+}^{n_{i}}$. The same result as (14) then holds. Thus, for expositional convenience, the integer assumption is maintained throughout.

${ }^{16}$ For (14) to hold, the assumption in (2) is not necessary. All that is needed is that the maximum of $x_{i h}$ for $h \in[1, \hat{h}]$ is smaller than or equal to the minimum of $x_{i h}$ for $h \in\left[\hat{h}, n_{i}\right]$, so that $U_{i h}^{x}$ for all $h \in[1, \hat{h}]$ exceeds $U_{i h}^{x}$ for all $h \in\left[\hat{h}, n_{i}\right]$. That is, unlike in (2), resident $h^{\prime}$ does not have to be richer than resident $h$ for all $h^{\prime}>h$, or $x_{i h}$ does not have to increase in $h$.
} 
capital is subsidized. This result can be stated as:

Proposition 1 Assume identical jurisdictions. (i) If $\delta_{i h}<(=,>) 0$ for $h<(=,>) \hat{h}, t_{i}^{*}>0$ (the equilibrium capital tax rate is positive). (ii) If $\delta_{i h}>(=,<) 0$ for $h<(=,>) \hat{h}, t_{i}^{*}<0$ (the equilibrium capital tax rate is negative).

The proposition stands in contrast with the standard result in the literature (Zodrow and Mieszkowski 1986; Bucovetsky and Wilson 1991) that if immobile factors are taxed to finance the public goods, mobile factors are not taxed. The reason for the standard result is that the taxation of mobile factors distorts the allocation of resources while the taxation of immobile factors amounts to lump-sum taxation. However, in this paper, even if immobile labor is taxed, mobile capital may be taxed or subsidized if the inequalities in (12) or (13) hold. This difference from the literature arises from the different factor-endowment distribution. The literature typically considers homogeneous residents in a jurisdiction with $\alpha_{i h}=\beta_{i h}=1 / n_{i}$ and $\delta_{i h}=0$ for all $h$, so that each resident owns the same amount of capital and labor. With homogeneous residents, (11) becomes zero and the equilibrium capital tax is zero.

The intuition can be gained as follows. An increase in the capital tax directly increases the capital tax revenues and hence the public good by $k_{i} f_{i}^{\prime}{ }^{17}$ The increase in $t_{i}$ also drives out capital, decreasing labor tax revenues by $\tau_{i} k_{i} f_{i}^{\prime \prime}\left(\partial k_{i} / \partial t_{i}\right)$. Since $k_{i} f_{i}^{\prime}>\tau_{i} k_{i} f_{i}^{\prime \prime}\left(\partial k_{i} / \partial t_{i}\right){ }^{18}$ an increase in $t_{i}$ increases the tax revenues and hence the public good by $k_{i} f_{i}^{\prime}-\tau_{i} k_{i} f_{i}^{\prime \prime}\left(\partial k_{i} / \partial t_{i}\right)$. The marginal welfare gain to the jurisdiction from this increased public good is $\sum U_{i h}^{z}\left(k_{i} f_{i}^{\prime}-\tau_{i} k_{i} f_{i}^{\prime \prime}\left(\partial k_{i} / \partial t_{i}\right)\right)=$ $\sum U_{i h}^{x} \beta_{i h}\left(k_{i} f_{i}^{\prime}-\tau_{i} k_{i} f_{i}^{\prime \prime}\left(\partial k_{i} / \partial t_{i}\right)\right)$ once the labor tax is chosen to satisfy the Samuelson-type condition. At the same time, an increase in the capital tax decreases private good consumption $x_{i h}$ in two ways. It decreases the net return to capital and hence capital income of resident $h$ by $-\alpha_{i h} \bar{k}_{i}\left(\partial \rho / \partial t_{i}\right)$. It also drives out capital and decreases the net labor incomes of resident $h$ by $\beta_{i h}\left(1-\tau_{i}\right) k_{i} f_{i}^{\prime \prime}\left(\partial k_{i} / \partial t_{i}\right)$. The marginal welfare loss to the jurisdiction from this decreased incomes is then $\sum U_{i h}^{x}\left[\alpha_{i h} \bar{k}_{i}\left(\partial \rho / \partial t_{i}\right)-\right.$ $\left.\beta_{i h}\left(1-\tau_{i}\right) k_{i} f_{i}^{\prime \prime}\left(\partial k_{i} / \partial t_{i}\right)\right]$. The change in jurisdictional welfare from the increase in the capital tax is thus $\sum U_{i h}^{x}\left[\alpha_{i h} \bar{k}_{i}\left(\partial \rho / \partial t_{i}\right)+\beta_{i h}\left(k_{i} f_{i}^{\prime}-k_{i} f_{i}^{\prime \prime}\left(\partial k_{i} / \partial t_{i}\right)\right)\right]$, which reduces to (10) and to (11) with identical jurisdictions. The change is thus proportional to $\sum U_{i h}^{x}\left(\beta_{i h}-\alpha_{i h}\right)$. This change is negative

\footnotetext{
${ }^{17}$ Although the increase in the capital tax drives out capital and decreases the capital tax revenues by $t_{i}\left(f_{i}^{\prime}+\right.$ $\left.k_{i} f_{i}^{\prime \prime}\right)\left(\partial k_{i} / \partial t_{i}\right)$, this distortionary effect of the capital tax on the public good vanishes at $t_{i}=0$.

${ }^{18}$ With identical jurisdictions, $\tau_{i} k_{i} f_{i}^{\prime \prime}\left(\partial k_{i} / \partial t_{i}\right)=\tau_{i} k_{i} f_{i}^{\prime}(q-1) / D f_{i}^{\prime \prime}=\tau_{i} k_{i} f_{i}^{\prime}(q-1) / q<k_{i} f_{i}^{\prime}$ at $t_{i}=0$ from (5).
} 
for the rich while it is positive for the poor if the rich own relatively more capital while the poor own relatively more labor, as in (12). As the rich's marginal utility counts less, the welfare loss for the rich is outweighed by the welfare gain for the poor and the net welfare gain from the increase in the capital tax is positive. As a consequence, an increase in $t_{i}$, starting from $t_{i}=0$, improves the jurisdictional welfare, implying that $t_{i}^{*}>0$ and capital is taxed in equilibrium. By contrast, if the rich own relatively more labor while the poor own relatively more capital, as in (13), the opposite holds and $t_{i}^{*}<0$.

\section{4-B Discussion}

As majority voting is an alternative way to determine the tax rates of a jurisdiction, this section discusses the difference from the voting outcome. A decision-making unit is an individual, and voter or resident $h$ of jurisdiction $i$ prefers to choose $\left(\tau_{i}, t_{i}\right)$ to maximize his utility $U_{i}\left(x_{i h}, z_{i}\right)$. The firstorder conditions would be the same as those in (9), except that $U_{i h}^{x}$ and $U_{i h}^{z}$ replace $\sum_{h=1}^{n_{i}} U_{i h}^{x}$ and $\sum_{h=1}^{n_{i}} U_{i h}^{z}$, respectively. As in (9), an increase in $t_{i}$ starting from $t_{i}=0$ decreases his private income by $\alpha_{i h} k_{i}\left(\partial \rho / \partial t_{i}\right)-\left(1-\tau_{i}\right) \beta_{i h} k_{i} f_{i}^{\prime \prime}\left(\partial k_{i} / \partial t_{i}\right)$, but increases the public good by $k_{i} f_{i}^{\prime}-\tau_{i} k_{i} f_{i}^{\prime \prime}\left(\partial k_{i} / \partial t_{i}\right)$.

Once the labor tax rate $\tau_{i}$ is chosen to maximize his utility, the value of the public good equals $\beta_{i h}$ times that of the private good. The net gain from an increase in $t_{i}$ to resident $h$ becomes then $\left(f_{i}^{\prime} k / D F_{i}^{\prime \prime}\right) U_{i h}^{x}\left(\beta_{i h}-\alpha_{i h}\right)$, equation (11) with $\sum_{h=1}^{n_{i}} U_{i h}^{x}$ replaced by $U_{i h}^{x}$. This equation is positive and resident $h$ prefers to tax capital if $\beta_{i h}>\alpha_{i h}$. Interpreting the increase in the public good by an increase in $t_{i}$ as a redistribution to resident $h$ from the rest (the average resident) of jurisdiction $i$, the condition means that the redistribution exceeds resident $h$ 's lost income due to the capital tax. Intuitively, when resident $h$ owns less capital relative to the jurisdiction (the average resident), the lost income is smaller while the redistribution is independent of his capital ownership, and resident $h$ prefers to tax capital (Borck 2003). ${ }^{19}$ This desire of resident $h$ to redistribute to himself from the rest of the jurisdiction is common in voting models with public goods, as in Meltzer and Richard (1981). If a majority of the residents of jurisdiction $i$ prefer to tax capital, then capital is taxed under majority voting.

\footnotetext{
${ }^{19}$ There is a large literature on voting on capital taxation with heterogeneous capital ownership (for example, Persson and Tabellini 1992; Kessler et al. 2002). However, their focus differs and do not consider why mobile capital is taxed even if non-distortionary taxes are available. In addition, even if the utility function is quasi-concave in the tax rates, voting equilibrium in general does not exist when there are multiple tax instruments, as in this paper. This non-existence may provide a justification for the jurisdictional-welfare approach adopted in this paper.
} 
The desire of resident $h$ to redistribute to himself from the rest of the jurisdiction does not apply to the jurisdictional welfare approach, taken in this paper. To see this, note that the decisionmaking unit is the government of jurisdiction $i$ and the approach takes into account the utilities of all residents of jurisdiction $i$. Since the analysis rules out a terms-of-trade effect that occurs between jurisdictions, capital taxation of a jurisdiction has no effect on the aggregate income of the jurisdiction. This can be seen by setting $U_{i h}^{x}=1$ for all $h$ in (11), so that the aggregate income gain by an increase in $t_{i},\left(f_{i}^{\prime} k / D f_{i}^{\prime \prime}\right) \sum_{h=1}^{n_{i}} \beta_{i h}=f_{i}^{\prime} k / D f_{i}^{\prime \prime}$, equals the loss, $\left(f_{i}^{\prime} k / D f_{i}^{\prime \prime}\right) \sum_{h=1}^{n_{i}} \alpha_{i h}=f_{i}^{\prime} k / D f_{i}^{\prime \prime}$ at $t_{i}=0$. That is, the redistribution benefit from an increase in the public good by an increase in $t_{i}$ just equals the jurisdiction's lost incomes, or a jurisdiction cannot redistribute to itself from itself. A jurisdiction that attempts to maximize its aggregate income would then set $t_{i}^{*}=0$ and would not tax or subsidize capital. For taxation or subsidization of capital to occur, the value or utility of income should differ across individuals of the jurisdiction. With diminishing marginal utility of income, the poor's income counts more than the rich's, and the jurisdiction that wishes to maximize the jurisdictional welfare desires to redistribute from the rich to the poor. Thus, redistribution plays an important role in the determination of capital taxes both in the voting approach and in the jurisdictional welfare approach, but the scope of redistribution differs. Redistribution occurs between a resident and the rest of the jurisdiction in the former approach, but between the rich and the poor of the jurisdiction in the latter approach. Analytically, resident $h$ prefers to tax capital if $\beta_{i h}>\alpha_{i h}$, but the jurisdiction does if $\sum_{h=1}^{n_{i}} U_{i h}^{x} \beta_{i h}>\sum_{h=1}^{n_{i}} U_{i h}^{x} \alpha_{i h}$.

The above discussion implies that capital in jurisdiction $i$ is taxed at a voting equilibrium if a majority of residents of the jurisdiction own more labor than capital, regardless of who, the rich or poor, own more labor than capital. That is, all that matters is that the number of residents with $\beta_{i h}>\alpha_{i h}$ exceeds $n_{i} / 2$. By contrast, the government of jurisdiction $i$ that aims to maximize its jurisdictional welfare taxes capital if condition (12) holds, so that the poor of the jurisdiction own more labor than capital (or the rich own more capital than labor), regardless of how many residents own more labor than capital. As a consequence of this difference, capital may be taxed at a voting equilibrium when the maximization of jurisdictional welfare dictates that capital should be subsidized, and vice-versa. Thus, in principle, the condition for the taxation of capital under majority voting can be more general or restrictive than that with maximization of jurisdictional 
welfare. However, under a plausible assumption that the poor own more labor than capital, (12) is satisfied and capital is taxed with maximization of jurisdictional welfare, but capital is not necessarily taxed under majority voting unless the poor with $\beta_{i h}>\alpha_{i h}$ are a majority. In this regard, capital is more likely to be taxed with maximization of jurisdictional welfare than under voting equilibrium. To see this difference through an example, suppose that $\beta_{i h}=1 / n_{i}$ for all $h$ and $\alpha_{i h^{\prime}}>\alpha_{i h}, h^{\prime}>h$. In this case, $\delta_{i h}=\alpha_{i h}-\left(1 / n_{i}\right)<(>) 0$ for the poor (rich), and (12) is satisfied. Capital is thus taxed with maximization of jurisdictional welfare. However, at a voting equilibrium, capital may not be taxed unless $\delta_{i h}<0$ for a majority of residents. An analogous discussion applies to the difference between the two approaches in the conditions under which capital is subsidized.

The desire of jurisdiction $i$ to redistribute from the rich to the poor, arising from the diminishing marginal utility of income, plays an important role in the taxation of capital. However, such desire does not necessarily lead to capital taxation. That is, jurisdictions tax capital, not simply because they want to redistribute from the rich to the poor. To see this point, consider two special cases. First, suppose that the first inequality of (2) becomes a weak inequality, so that $\alpha_{i h}=1 / n_{i}$ for all $h$ and $\beta_{i h^{\prime}}>\beta_{i h}$. Resident $h^{\prime}$ is thus still richer than resident $h$, but capital is not taxed but subsidized, because $\delta_{i h}=\left(1 / n_{i}\right)-\beta_{i h}>(<) 0$ for the poor (rich) and hence part (ii) of the proposition applies to this case. Intuitively, with $\alpha_{i h}=1 / n_{i}$ for all $h$, everyone loses the same income from capital taxation, but the poor lose more in utility. In addition, since the poor own less labor, and since the benefit from capital taxation (the increased public good) is proportional to labor ownership, $\beta_{i h}$, the benefit is lower for the poor. As the poor's utilities count more, the jurisdiction subsidizes capital. Second, suppose that (2) holds, but $\alpha_{i h}=\beta_{i h}$ or $\delta_{i h}=0$ for all $h$. A richer resident then owns more capital and more labor than a poorer resident, but the government for jurisdiction $i$ does not tax capital, because the capital tax has no advantage or disadvantage over the labor tax. In fact, (11) becomes zero and $t_{i}^{*}=0$ with $\delta_{i h}=\alpha_{i h}-\beta_{i h}=0$ for all $h$, and neither part (i) nor part (ii) of the proposition applies to this case. This special case shows that even if the rich own more capital than the poor, capital is not necessarily taxed.

To sharpen the argument that redistribution is neither necessary nor sufficient for the taxation of mobile capital, consider a different objective of the government for jurisdiction $i$, other than the utilitarian social-welfare function with a diminishing marginal utility of income. Suppose for 
example that the government of jurisdiction $i$ selects the tax rates $\left(t_{i}, \tau_{i}\right)$ to maximize the sum of the utilities of residents in group $G$, for example, because policymakers of jurisdiction $i$ view the group as representing the jurisdiction. In addition, assume that the utility function is written as $U_{i}\left(x_{i h}, z\right)=\theta x_{i h}+\omega(z)$ with $\theta$ denoting a positive constant, so that the marginal utility of private good, $\theta$, does not depend on incomes. Applying the steps, analogous to those leading to (11), it is straightforward to verify that (11) becomes

$$
\left.\frac{d}{d t_{i}} \sum_{h \in G} U_{i h}\left(x_{i h}, z_{i}\right)\right|_{\left(t_{i}=0\right)}=\frac{f_{i}^{\prime} k}{D f_{i}^{\prime \prime}} \sum_{h \in G} U_{i h}^{x}\left(\beta_{i h}-\alpha_{i h}\right)=\frac{f_{i}^{\prime} k}{D f_{i}^{\prime \prime}} \theta \sum_{h \in G}\left(\beta_{i h}-\alpha_{i h}\right) .
$$

Thus, $t_{i}>(=,<) 0$ if $\sum_{h \in G} \beta_{i h}>(=,<) \sum_{h \in G} \alpha_{i h}$, and jurisdiction $i$ taxes (subsidizes) capital if the residents in $G$ own more (less) labor than capital. The decision of the jurisdiction to tax or subsidize capital has no relation to the desire to redistribute, because the utility function is linear in incomes. This discussion illustrates that the desire for redistribution is not a necessary condition for a jurisdiction to tax or subsidize mobile capital.

\section{4-C Factor Ownership}

This section discusses if condition (12) is satisfied in reality. Table 1 borrows from Green et al. (1990,

Table 2) and Davies et al. (2007, Table 1), and shows the distribution of earnings and wealth across quintiles for five countries that have comparable data. ${ }^{20}$ Earnings in Table 1 represent wages and salaries, and can be considered labor incomes. Wealth represents financial and real assets. Since the returns to wealth can be considered capital incomes, the distribution of wealth would approximate that of capital incomes.

Translating the data in the table to factor ownership parameters in the model, the data for Australia in the first panel of Table 1 implies

$$
\begin{gathered}
\beta_{1}=.082, \beta_{2}=.154, \beta_{3}=.19, \beta_{4}=.233, \beta_{5}=.341, \\
\alpha_{1}=0, \alpha_{2}=.04, \alpha_{3}=.12, \alpha_{4}=.22 \alpha_{5}=.62,
\end{gathered}
$$

\footnotetext{
${ }^{20} \mathrm{~A}$ large number of data sets for income distributions are available. However, such data sets are not suitable for the purpose of this paper, as most of the data do not include detailed distributions of incomes such as distribution across deciles or quintiles, as in Table 1. Rather, they have information about top $5 \%$ or top $10 \%$ or median incomes. An analgous comment applies to wealth data sets. Even in Table 1, earnings data and wealth data may not be directly comparable, because most of the earnings data are for the mid 1980's while most of the wealth data are for the late 1990's. However, this difference does not appear to be significant, because the distributions of earnings usually change little over 5 or 10 years. For example, the distributions of earnings changed less than $1 \%$ point for each quintile between the early 1980's and the mid 1980's or between the late 1970's and the late 1980's (Green et al. 1990, Table 6).
} 
where subscripts $h$ denote each quintile income group, $h=1,2,3,4,5$. The difference between $\alpha$ and $\beta$ is then

$$
\delta_{1}=-.082<0, \delta_{2}=-.114<0, \delta_{3}=-.07<0, \delta_{4}=-.013<0, \delta_{5}=.279>0
$$

The inequalities above satisfy the condition in (12), as the richest group, group 5, own more capital than labor while the remaining groups own more labor than capital. It is easy to verify that the same pattern of $\delta \mathrm{s}$ holds for other countries in the table. ${ }^{21}$

In addition to the data in Table 1, a distribution of income from capital is known to be in general more unequal than a labor income distribution. For example, Goodman et al. (1997) and Diaz-Gimenez et al. (1997) document this known fact for the United Kingdom and the United States, respectively, although they do not document detailed distributions of incomes. These examples illustrate another possibility of the inequalities in (12).

Taken together, part of (i) Proposition 1 is more likely to apply than part (ii), and capital is more likely to be taxed than subsidized in equilibrium. This conclusion accords well with the observation that mobile capital is taxed in reality. For instance, the effective capital tax rates for European Union countries and for OECD countries are typically about 30\% (Haufler 2001; Chen et al. 2007).

\section{Efficiency of Tax Competition}

The paper mainly concerns a positive question of whether jurisdictions tax mobile capital in the presence of non-distortionary taxes. However, efficiency of tax competition has been extensively discussed in the literature, and this section considers the efficiency issue. As the analysis focuses on symmetric jurisdictions, the number of jurisdictions has no qualitative effect on the analysis and two symmetric jurisdictions, $i$ and $j$, are assumed. Given that inefficiency of tax competition stems from the mobility of capital, efficient tax rates for jurisdiction $i$ are the rates that maximize its welfare $V_{i}$ with $\partial k_{i} / \partial t_{i}=0$. Given symmetric jurisdictions, the efficient tax rates are the same for both jurisdictions. The first-order conditions for an interior maximum of $V_{i}$ with respect to the efficient

\footnotetext{
${ }^{21}$ For Italy, no wealth data is available for the third and fourth quintiles, but $\delta_{1}<0, \delta_{2}<0$ and $\delta_{5}>0$. Thus, the same pattern holds among those three groups for which the data are available.
} 
tax rates read as

$$
\begin{gathered}
\frac{d V_{i}}{d \tau_{i}}=\left(f_{i}-k_{i} f_{i}^{\prime}\right) \sum_{h=1}^{n_{i}}\left[U_{i h}^{z}-U_{i h}^{x} \beta_{i h}\right]=0 \Longrightarrow \sum_{h=1}^{n_{i}} U_{i h}^{z}-\sum_{h=1}^{n_{i}} U_{i h}^{x} \beta_{i h}=0, \\
\frac{d V_{i}}{d t_{i}}=\sum_{h=1}^{n_{i}}\left[U_{i h}^{x} \alpha_{i h} \bar{k}_{i}\left(-f_{i}^{\prime}\right)+U_{i h}^{z} k_{i} f_{i}^{\prime}\right]=0 \Longrightarrow \sum_{h=1}^{n_{i}} U_{i h}^{z}-\sum_{h=1}^{n_{i}} U_{i h}^{x} \alpha_{i h}=0 .
\end{gathered}
$$

The condition for efficient $\tau_{i}$ is the same as that in (9), as the labor tax is non-distortionary. The condition for efficient $t_{i}$ assumes $\partial k_{i} / \partial t_{i}=0$ and hence $\partial \rho / \partial t_{i}=\partial\left(\left(1-t_{i}\right) f_{i}^{\prime}\right) / \partial t_{i}=-f_{i}^{\prime}$, along with $k_{i}=k_{j}=\bar{k}=k$.

If $\alpha_{i h}=\beta_{i h}=1 / n_{i}$ for all $h$, as in the standard model with identical residents, the two conditions in (15) coincide, and it does not matter which factor is taxed. Intuitively, since both capital and labor are fixed factors without mobility of capital, the tax on either factor is essentially a lump-sum tax. However, with heterogeneous factor ownership, the welfare loss from taxation differs between the two taxes, and the two taxes are not equivalent. Assume that (12) holds, because an analogous analysis applies to the case where (13) holds. The inequalities in (12) imply $\sum_{h=1}^{n_{i}} U_{i h}^{x} \beta_{i h}>\sum_{h=1}^{n_{i}} U_{i h}^{x} \alpha_{i h}$, and the two conditions in (15) cannot hold simultaneously, and there are two possibilities. First, $d V_{i} / d \tau_{i}=0$, and $d V_{i} / d t_{i}>0$. The efficient capital tax rate is then the maximum rate (equal to one in the absence of any institutional constraints), and it exceeds the equilibrium tax rate that satisfies (9). Second, $d V_{i} / d t_{i}=0$, and $d V_{i} / d \tau_{i}<0$. The labor tax rate is set at a minimum possible level however it is determined. The main concern is the relationship between the efficient capital tax rate and the equilibrium capital tax rate. Evaluating the second condition of (9) at the efficient capital tax rate, $\hat{t}_{i}$, that satisfies $(15)$,

$$
\begin{gathered}
\left.\frac{d V_{i}}{d t_{i}}\right|_{\left(t_{i}=\hat{t}_{i}\right)}=\sum_{h=1}^{n_{i}}\left[U_{i h}^{x}\left(\alpha_{i h} \bar{k}_{i} \frac{\partial \rho}{\partial t_{i}}-\left(1-\tau_{i}\right) \beta_{i h} k_{i} f_{i}^{\prime \prime} \frac{\partial k_{i}}{\partial t_{i}}\right)+U_{i h}^{x} \alpha_{i h}\left(k_{i} f_{i}^{\prime}+\left(t_{i} f_{i}^{\prime}+t_{i} k_{i} f_{i}^{\prime \prime}-\tau_{i} k_{i} f_{i}^{\prime \prime}\right) \frac{\partial k_{i}}{\partial t_{i}}\right)\right] \\
=\sum_{h=1}^{n_{i}}\left[U_{i h}^{x}\left(\alpha_{i h} \bar{k}_{i} \frac{\partial \rho}{\partial t_{i}}-\left(1-\tau_{i}\right) \alpha_{i h} k_{i} f_{i}^{\prime \prime} \frac{\partial k_{i}}{\partial t_{i}}\right)+U_{i h}^{x} \alpha_{i h}\left(k_{i} f_{i}^{\prime}+\left(t_{i} f_{i}^{\prime}+t_{i} k_{i} f_{i}^{\prime \prime}-\tau_{i} k_{i} f_{i}^{\prime \prime}\right) \frac{\partial k_{i}}{\partial t_{i}}\right)\right] \\
+\sum_{h=1}^{n_{i}} U_{i h}^{x}\left[\left(1-\tau_{i}\right) \alpha_{i h} k_{i} f_{i}^{\prime \prime} \frac{\partial k_{i}}{\partial t_{i}}-\left(1-\tau_{i}\right) \beta_{i h} k_{i} f_{i}^{\prime \prime} \frac{\partial k_{i}}{\partial t_{i}}\right] \\
=\sum_{h=1}^{n_{i}} U_{i h}^{x} \alpha_{i h}\left[\bar{k}_{i} \frac{\partial \rho}{\partial t_{i}}-k_{i} f_{i}^{\prime \prime} \frac{\partial k_{i}}{\partial t_{i}}+k_{i} f_{i}^{\prime}+\left(t_{i} f_{i}^{\prime}+t_{i} k_{i} f_{i}^{\prime \prime}\right) \frac{\partial k_{i}}{\partial t_{i}}\right] \\
+\sum_{h=1}^{n_{i}} U_{i h}^{x}\left(1-\tau_{i}\right)\left(\alpha_{i h}-\beta_{i h}\right) k_{i} f_{i}^{\prime \prime} \frac{\partial k_{i}}{\partial t_{i}}
\end{gathered}
$$




$$
=\sum_{h=1}^{n_{i}} U_{i h}^{x} \alpha_{i h} t_{i} f_{i}^{\prime} \frac{\partial k_{i}}{\partial t_{i}}+\sum_{h=1}^{n_{i}} U_{i h}^{x}\left(1-\tau_{i}\right)\left(\alpha_{i h}-\beta_{i h}\right) k_{i} f_{i}^{\prime \prime} \frac{\partial k_{i}}{\partial t_{i}}<0 .
$$

The first equality uses $\sum_{h=1}^{n_{i}} U_{i h}^{z}=\sum_{h=1}^{n_{i}} U_{i h}^{x} \alpha_{i h}$ in (15). The next one is obtained by subtracting and adding the same term, $\sum_{h=1}^{n_{i}} U_{i h}^{x}\left(1-\tau_{i}\right) \alpha_{i h} k_{i} f_{i}^{\prime \prime} \frac{\partial k_{i}}{\partial t_{i}}$, to the first line. The third equality comes from simplification of the terms in the second line. The last one uses $\partial \rho / \partial t_{i}=-f_{i}^{\prime}+\left(1-t_{i}\right) f_{i}^{\prime \prime}\left(\partial k_{i} / \partial t_{i}\right)$. The inequality comes from the assumption that (12) holds and $\sum_{h=1}^{n_{i}} U_{i h}^{x} \beta_{i h}>\sum_{h=1}^{n_{i}} U_{i h}^{x} \alpha_{i h}$. The inequality in (16) implies that the equilibrium capital tax rate is lower than the efficient level. Thus, regardless of which of (15) holds as equality, the equilibrium capital tax rate is lower than the efficient level. This inefficiency of tax competition implies that tax coordination among jurisdictions would improve efficiency even if each jurisdiction chooses its tax rates to maximize its welfare.

To understand (16), consider first the standard homogeneous factor ownership case with $\alpha_{i h}=$ $\beta_{i h}=1 / n_{i}$. The term involving the second summation vanishes, and (16) reduces to the standard term, $\sum_{h=1}^{n_{i}} U_{i h}^{x} \alpha_{i h} t_{i} f_{i}^{\prime} \frac{\partial k_{i}}{\partial t_{i}}<0$. This standard negative term reflects a decrease in the tax revenue of jurisdiction $i$, caused by an increase in $t_{i}$ and the resulting outflow of capital from jurisdiction $i$ to $j$. The outflow of capital also increases the tax revenue of jurisdiction $j$, canceling out the decrease in the revenue of jurisdiction $i$ with symmetric jurisdictions. The social planner that cares about the welfare of both jurisdictions $i$ and $j$ thus does not consider this standard negative term when choosing the efficient tax rate. As a result, the efficient tax rate exceeds the equilibrium tax rate. Alternatively speaking, jurisdiction $i$ does not consider the external benefit that jurisdiction $j$ enjoys due to the increased tax revenue, and sets its tax rate at a level lower than the efficient level. ${ }^{22}$ It is worth relating this standard case to Bucovetsky and Wilson (1991). In their model, even if jurisdictions tax only labor, tax competition is still inefficient, because labor supply is endogenous. In particular, an increase in the labor tax rate of a jurisdiction reduces the labor supply of the jurisdiction. This decrease in the labor supply reduces the demand for capital by a jurisdiction, increasing the supply of capital available to other jurisdictions and benefiting other jurisdictions. The jurisdiction, however, does not consider this external benefit on other jurisdictions, resulting in too low a tax rate on labor and underprovision of public goods. In this paper, labor taxation is non-distortionary, but capital taxation creates an inefficiency for the reason mentioned above.

\footnotetext{
${ }^{22} \mathrm{~A}$ simple calculation shows that $d V_{j} / d t_{i}$, the external effect of an increase in $t_{i}$ on jurisdiction $j$, coincides with (16), except that subscripts $i$ and $j$ are switched. Since $\partial k_{j} / \partial t_{i}>0$, this external effect is positive and tax competition creates a positive externality.
} 
With heterogeneous factor ownership, the term involving the second summation in (16) does not vanish. By the assumption that (12) holds, $\sum_{h=1}^{n_{i}} U_{i h}^{x}\left(\alpha_{i h}-\beta_{i h}\right)<0$ and hence $\sum_{h=1}^{n_{i}} U_{i h}^{x}(1-$ $\left.\tau_{i}\right)\left(\alpha_{i h}-\beta_{i h}\right) k_{i} f_{i}^{\prime \prime} \frac{\partial k_{i}}{\partial t_{i}}<0$. To understand this negative term, note first that all terms in the first line of (16) involve $\alpha_{i h}$, except $-\left(1-\tau_{i}\right) \beta_{i h} k_{i} f_{i}^{\prime \prime} \frac{\partial k_{i}}{\partial t_{i}}$, the loss of after-tax labor incomes due to the outflow of capital from jurisdiction $i$ to $j$. Since the poor own relatively more labor and their utilities count more, the outflow of capital additionally decreases the welfare of jurisdiction $i$, relative to the case where $\beta_{i h}=\alpha_{i h}$ for all $h$, because in that case there would be no additional decrease in the welfare. The social planner again does not consider this negative term, because the outflow of capital to jurisdiction $j$ increases labor incomes of the residents of jurisdiction $j$ and hence increases the welfare of jurisdiction $j$, canceling out the decrease in the welfare of jurisdiction $i$. Alternatively speaking, jurisdiction $i$ ignores this external benefit that jurisdiction $j$ enjoys due to the increased welfare from heterogeneous factor ownership, and sets its tax rate at too low a level. As a result, heterogeneous factor ownership exacerbates the undertaxation of capital by jurisdiction $i$. Intuitively, jurisdiction $i$ ignores not only the standard external benefit that the capital outflow to jurisdiction $j$ increases its tax base, but also the additional external benefit that the welfare of jurisdiction $j$ increases due to the poor owning relatively more labor.

\section{Extensions}

\section{6-A Progressive Labor Taxes}

In the previous sections, all residents of jurisdiction $i$ paid the same labor tax rate, $\tau_{i}$. It might be argued that if the rich can be taxed more heavily, then the public good can be provided without taxing mobile capital, as the government for a jurisdiction simply relies more on the non-distortionary labor tax. However, as the analysis below shows, capital is still taxed.

Suppose that two labor tax rates, $\tau_{L}$ and $\tau_{H}$ with $\tau_{H}>\tau_{L}$, exist. ${ }^{23}$ Labor incomes up to $M$ are taxed at the rate of $\tau_{L}$, and at the rate of $\tau_{H}$ thereafter. Without loss of generality, assume that there is a resident $h^{*} \in\left(1, n_{i}\right)$ such that

$$
\beta_{i h}\left(f_{i}-k_{i} f_{i}^{\prime}\right)<(=,>) M \text { for } h<(=,>) h^{*} .
$$

\footnotetext{
${ }^{23}$ The tax rates should be written as $\tau_{i L}$ and $\tau_{i H}$, but jurisdictional subscripts $i$ are omitted for simplicity. In addition, the analysis and results continue to hold with more than two labor tax rates, as shown in an earlier version of this paper.
} 
For later use, let $L \equiv\left\{h \mid h \leq h^{*}\right\}$ denote the set of the poor with labor incomes less than $M$, and similarly for $H \equiv\left\{h \mid h \geq h^{*}\right\}$. Then, $x_{i h}$ becomes

$$
x_{i h}=\left\{\begin{array}{cc}
\alpha_{i h} \bar{k}_{i} \rho+\beta_{i h}\left(1-\tau_{L}\right)\left(f_{i}-k_{i} f_{i}^{\prime}\right) & \text { if } h \in L \\
\alpha_{i h} \bar{k}_{i} \rho+\beta_{i h}\left(1-\tau_{H}\right)\left(f_{i}-k_{i} f_{i}^{\prime}\right)+\left(\tau_{H}-\tau_{L}\right) M & \text { if } h \in H,
\end{array}\right.
$$

and

$$
z_{i}=t_{i} k_{i} f_{i}^{\prime}+\left(\tau_{L} b_{L}+\tau_{H} b_{H}\right)\left(f_{i}-k_{i} f_{i}^{\prime}\right)-\left(\tau_{H}-\tau_{L}\right) M\left(n_{i}-h^{*}\right) \text { with } b_{L} \equiv \sum_{h \in L} \beta_{i h} \text { and } b_{H} \equiv \sum_{h \in H} \beta_{i h}
$$

because there are $\left(n_{i}-h^{*}\right)$ rich residents in $H$.

Jurisdiction $i$ selects $\left(M, \tau_{L}, \tau_{H}, t_{i}\right)$ to maximize its welfare $V_{i}$. Using the first-order conditions, it can be shown in the Appendix that

$$
\left.\frac{d V_{i}}{d t_{i}}\right|_{\left(t_{i}=0\right)}>\left.\frac{d V_{i}}{d t_{i}}\right|_{\left(t_{i}=0, \tau_{L}=\tau_{H}=\tau\right)}=\frac{k f_{i}^{\prime}}{D f_{i}^{\prime \prime}} \sum_{h=1}^{n_{i}} U_{i h}^{x}\left[-\delta_{i h}\right] .
$$

Noting that the last expression of (20) is identical to the one in (11) with the single labor tax, the following result can be stated:

Proposition 2 Assume identical jurisdictions. With progressive labor taxes, $t_{i}^{*}>0$ (the equilibrium capital tax rate is positive) if $\delta_{i h}<(=,>) 0$ for $h<(=,>) \hat{h}$.

The intuition of the result is the same as that of Proposition 1, and the result that if (12) holds, capital is taxed in equilibrium extends to the progressive labor tax case. The only difference is that if (13) holds, capital may be still taxed here due to the inequality in (20) while capital was subsidized in Proposition 1. The progressive taxes thus make it more likely that capital is taxed in equilibrium. The key to this result is that with the progressive labor tax, $\sum_{h=1}^{n_{i}} U_{i h}^{z}>\sum_{h=1}^{n_{i}} U_{i h}^{x} \beta_{i h}$, and the Samuelson-type condition in (9), $\sum_{h=1}^{n_{i}} U_{i h}^{z}=\sum_{h=1}^{n_{i}} U_{i h}^{x} \beta_{i h}$, does not hold. Intuitively, jurisdiction $i$ desires to tax the labor incomes of higher income residents, $h \in H$, to the maximum extent possible. As it cannot tax more than $100 \%$ of the labor incomes, the labor tax for those high income residents is set at $\tau_{H}=1$, and is lower than the maximization of the jurisdictional welfare dictates (that is, the constraint on the tax rate, $\tau_{H} \leq 1$, is binding). The public good is thus lower than the maximization of the jurisdictional welfare dictates, and $\sum_{h=1}^{n_{i}} U_{i h}^{z}>\sum_{h=1}^{n_{i}} U_{i h}^{x} \beta_{i h}$. To relate this to the capital tax, recall from the discussion of Proposition 1 that the jurisdictional net welfare gain from capital taxation is proportional to $\sum U_{i h}^{x} \beta_{i h}-\sum U_{i h}^{x} \alpha_{i h}$ once the labor tax is chosen to satisfy 
the first-order condition $\sum_{h=1}^{n_{i}} U_{i h}^{z}=\sum_{h=1}^{n_{i}} U_{i h}^{x} \beta_{i h}$. With the progressive labor tax, the condition is not satisfied and $\sum_{h=1}^{n_{i}} U_{i h}^{z}>\sum_{h=1}^{n_{i}} U_{i h}^{x} \beta_{i h}$, meaning that the jurisdictional net welfare gain from capital taxation is more than proportional to $\sum U_{i h}^{x} \beta_{i h}-\sum U_{i h}^{x} \alpha_{i h}$. As a result, the progressive labor tax increases the net welfare gain from capital taxation, and capital is more likely to be taxed than in Proposition 1.

\section{6-B Transfers}

This section assumes that the tax revenues are used to provide the public good and a lump-sum transfer, $T_{i}$, for all residents of jurisdiction $i$. The government for jurisdiction $i$ chooses $\left(T_{i}, M, \tau_{L}, \tau_{H}, t_{i}\right)$ to maximize $V_{i}=\sum_{h=1}^{n_{i}} U_{i}\left(y_{i h}, R_{i}-n_{i} T_{i}\right)$ with $y_{i h} \equiv x_{i h}+T_{i}$, where $x_{i h}$ is defined in (18) and $R_{i}$ is identical to the expression in (19). The first-order condition for an interior maximum of $V_{i}$ with respect to $T_{i}$ reads as

$$
\frac{d V_{i}}{d T_{i}}=\sum_{h=1}^{n_{i}}\left[U_{i h}^{y}-n_{i} U_{i h}^{z}\right]=0,
$$

and the other four conditions are identical to those in (23) through (26) in the Appendix with $U_{i h}^{y}$ replacing $U_{i h}^{x}$. If $M$ is chosen to satisfy (23), $d V_{i} / d T_{i}=\sum_{h=1}^{n_{i}}\left[\left(n_{i}-h^{*}\right) U_{i h}^{z}-n_{i} U_{i h}^{z}\right]<0$, resulting in $T_{i}=0$. As a result, the analysis and result in the previous section continues to hold, and capital is taxed in equilibrium if (12) holds. Intuitively, by choosing $M$ and $\tau_{L}$ and by taxing the rich's labor incomes at the maximum rate $\left(\tau_{H}=1\right)$, jurisdiction $i$ achieves a maximum redistribution within the progressive tax system, obviating the need for $T_{i}$.

To have a meaningful role of transfers with $T_{i}>0$, consider a single labor tax with transfers $T_{i}{ }^{24}$ Jurisdiction $i$ then chooses $\left(T_{i}, \tau_{i}, t_{i}\right)$. The first-order conditions are then (21) and the two conditions in (9) with $U_{i h}^{y}$ replacing $U_{i h}^{x}$. If $T_{i}$ is chosen to satisfy $(21), d V_{i} / d \tau_{i}=\left(f_{i}-\right.$ $\left.k_{i} f_{i}^{\prime}\right) \sum_{h=1}^{n_{i}} U_{i h}^{y}\left[\left(1 / n_{i}\right)-\beta_{i h}\right]>0$ in (9), because the average of $\beta_{i h}$ equals $1 / n_{i}$, and because $\beta_{i h}$ increases in income while $U_{i h}^{y}$ decreases in income. Thus, $\tau_{i}=1$. With (21) and $\tau_{i}=1, d V_{i} / d t_{i}$ in (9) at $t_{i}=0$ becomes

$$
\begin{aligned}
\left.\frac{d V_{i}}{d t_{i}}\right|_{\left(t_{i}=0\right)} & =\sum_{h=1}^{n_{i}} U_{i h}^{y} \alpha_{i h} \bar{k}_{i} \frac{\partial \rho}{\partial t_{i}}+\sum_{h=1}^{n_{i}} U_{i h}^{z}\left[k_{i} f_{i}^{\prime}-k_{i} f_{i}^{\prime \prime} \frac{\partial k_{i}}{\partial t_{i}}\right] \\
& =-\frac{k f_{i}^{\prime}}{D f_{i}^{\prime \prime}} \sum_{h=1}^{n_{i}} U_{i h}^{y} \alpha_{i h}+\frac{k f_{i}^{\prime}}{D f_{i}^{\prime \prime}} \sum_{h=1}^{n_{i}} U_{i h}^{z}
\end{aligned}
$$

\footnotetext{
${ }^{24}$ The tax system thus becomes a linear tax.
} 


$$
\begin{gathered}
=-\frac{k f_{i}^{\prime}}{D f_{i}^{\prime \prime}} \sum_{h=1}^{n_{i}} U_{i h}^{y} \alpha_{i h}+\frac{k f_{i}^{\prime}}{D f_{i}^{\prime \prime}} \sum_{h=1}^{n_{i}} U_{i h}^{y} \frac{1}{n_{i}} \\
=\frac{k f_{i}^{\prime}}{D f_{i}^{\prime \prime}} \sum_{h=1}^{n_{i}} U_{i h}^{y}\left(\frac{1}{n_{i}}-\alpha_{i h}\right)>0 .
\end{gathered}
$$

The inequality follows because the average of $\alpha_{i h}$ equals $1 / n_{i}$, and because $\alpha_{i h}$ increases in income while $U_{i h}^{y}$ decreases in income. This result is summarized as:

Proposition 3 Assume identical jurisdictions. $t_{i}^{*}>0$ (the equilibrium capital tax rate is positive) if the tax revenues are used to provide the public good and a lump-sum transfer.

The result that capital is taxed in equilibrium thus extends to the case with the public good and lump-sum transfer. The intuition can be explained as follows. Recall again from the discussion of Proposition 1 that the marginal welfare gain from the increased public good, caused by an increase in $t_{i}$, is $\sum U_{i h}^{z}\left(k_{i} f_{i}^{\prime}-\tau_{i} k_{i} f_{i}^{\prime \prime}\left(\partial k_{i} / \partial t_{i}\right)\right)=\sum U_{i h}^{y}\left(k_{i} f_{i}^{\prime}-k_{i} f_{i}^{\prime \prime}\left(\partial k_{i} / \partial t_{i}\right)\right) / n_{i}$, because the transfer $T_{i}$ is chosen to satisfy another Samuelson-type condition, $\sum U_{i h}^{z}=\sum U_{i h}^{y} / n_{i}$ in (21), and because $\tau_{i}=1$. The marginal welfare loss from the decreased incomes is $\sum U_{i h}^{y}\left[\alpha_{i h} \bar{k}_{i}\left(\partial \rho / \partial t_{i}\right)-\beta_{i h}\left(1-\tau_{i}\right) k_{i} f_{i}^{\prime \prime}\left(\partial k_{i} / \partial t_{i}\right)\right]=$ $\sum U_{i h}^{y} \alpha_{i h} \bar{k}_{i}\left(\partial \rho / \partial t_{i}\right)$ with $\tau_{i}=1$. The net welfare gain thus becomes $\sum U_{i h}^{y}\left[\alpha_{i h} \bar{k}_{i}\left(\partial \rho / \partial t_{i}\right)+\left(k_{i} f_{i}^{\prime}-\right.\right.$ $\left.\left.k_{i} f_{i}^{\prime \prime}\left(\partial k_{i} / \partial t_{i}\right)\right) / n_{i}\right]$, which reduces to $(22)$ and is proportional to $\sum_{h=1}^{n_{i}} U_{i h}^{y}\left(\left(1 / n_{i}\right)-\alpha_{i h}\right)$. Since the rich own more capital and their marginal utility counts less, the last expression is positive and capital is taxed in equilibrium. The difference from Proposition 1 is that capital is taxed, regardless of whether (12) holds or (13) holds, as long as the rich own more capital. That is, the distribution of labor endowments, $\beta_{i h}$, does not matter in this section, because the optimal choice of lump-sum transfer $T_{i}$ results in the maximum labor tax, $\tau_{i}=1$, and hence the labor incomes vanish. ${ }^{25}$

Suppose alternatively that $\tau_{i}$ is chosen to satisfy $d V_{i} / d \tau_{i}=0$ in (9) with $U_{i h}^{y}$ replacing $U_{i h}^{x}$. In this case, it is easy to verify that $d V_{i} / d T_{i}=\sum_{h=1}^{n_{i}}\left[U_{i h}^{y}-n_{i} U_{i h}^{z}\right]=\sum_{h=1}^{n_{i}}\left[U_{i h}^{y}-n_{i} \beta_{i h} U_{i h}^{y}\right]=$ $n_{i} \sum_{h=1}^{n_{i}} U_{i h}^{y}\left[\left(1 / n_{i}\right)-\beta_{i h}\right]>0$ in $(21)$, and the transfer, $T_{i}$, is set at a maximum level. Intuitively, the labor tax is chosen to satisfy the Samuelson-type condition for an optimal level of the public good, and the only role that the transfer plays in maximizing the jurisdictional welfare $V_{i}$ is then to maximize redistribution. Thus, the transfer is set at a maximum level, because the rich pay more taxes to finance the transfers while everyone receives the same transfer. The maximum $T_{i}$

\footnotetext{
${ }^{25}$ It is clear that even if the tax revenues are used only for redistribution, the same result would hold and capital would be taxed in equilibrium. Proposition 3 thus extends to the case with lump-sum transfers only. A formal analysis of this case was presented in an earlier version, but is omitted to conserve space.
} 
equals $R_{i} / n_{i}$. This means that the tax revenues are used only for transfers and no public good is provided. The utility of resident $h$ becomes then $U_{i}\left(x_{i h}+R_{i} / n_{i}, 0\right)$. If zero public good provision is possible as an outcome of maximizing welfare, as is the case for an additively- separable utility function between private good consumption and public good consumption, then the analysis reduces to the pure redistribution case above. Capital is again then taxed in equilibrium as long as the rich own more capital. If zero public good provision is not possible, as is the case for a Cobb-Douglas utility function of $U(x, z)=x^{A} z^{B}$, then the maximum transfer cannot be determined without further assumptions. With a pre-determined minimum public good level, say $\underline{z}$, as is the case for a Stone-Geary utility function, the maximum transfer $T_{i}$ equals $\left(R_{i}-\underline{z}\right) / n_{i}$. The utility of resident $h$ becomes then $U_{i}\left(x_{i h}+\left(R_{i}-\underline{z}\right) / n_{i}, \underline{z}\right)$. Since $\underline{z}$ is a parameter, the conditions that govern the jurisdictional welfare-maximizing tax rates are the same as those in the pure redistribution case. Capital is thus again taxed in equilibrium. Therefore, Proposition 3 extends to the case where the labor tax is chosen optimally to maximize the jurisdictional welfare.

\section{Conclusion}

According to the standard economic models of capital tax competition, capital is not taxed when immobile factors are taxed. The reason is that capital moves between jurisdictions in response to the tax rate differentials and capital tax is distortionary. Thus, the government for a jurisdiction that aims to maximize the well being of its residents does not tax capital when the taxes on immobile factors are available. However, in reality, capital is taxed despite the taxes on immobile factors. To be consistent with this realism, this paper has considered a simple model that explains why mobile capital is taxed even if immobile factors are taxed. The main argument relies on heterogeneity of residents in terms of their factor endowments. Heterogeneity in factor endowments has not received much attention, but appears to warrant more research. 
Table 1: \% Distribution of earnings and wealth across quintiles

\begin{tabular}{c|ccccc} 
countries & Lowest & Second & Third & Fourth & Highest \\
\hline $\begin{array}{c}\text { Australia } \\
\text { earnings } \\
\text { wealth }\end{array}$ & 8.2 & 15.4 & 19 & 23.3 & 34.1 \\
& 0 & 4 & 12 & 22 & 62 \\
\hline $\begin{array}{c}\text { Canada } \\
\text { earnings } \\
\text { wealth }\end{array}$ & 5.2 & 13.3 & 18.9 & 24.7 & 37.9 \\
\hline Germany & 0 & 3 & 8 & 19 & 70 \\
earnings & 8.9 & 15.3 & 18.7 & 22.8 & 34.3 \\
wealth & -.2 & 1.7 & 7.5 & 25 & 66 \\
\hline $\begin{array}{c}\text { Italy } \\
\text { earnings } \\
\text { wealth }\end{array}$ & 10.3 & 16.7 & 18.9 & 22 & 32.1 \\
\hline $\begin{array}{c}\text { Sweden } \\
\text { earnings }\end{array}$ & 7.2 & 16 & 19 & 22.7 & 35.1 \\
wealth & -6.8 & .2 & 6 & 20.5 & 80.1 \\
\hline
\end{tabular}




\section{Appendix}

\section{proof of $(20)$}

The first-order conditions for an interior maximum of $V_{i}=\sum_{h=1}^{n_{i}} U_{i}\left(x_{i h}, z_{i}\right)$ with respect to $\left(M, \tau_{L}, \tau_{H}, t_{i}\right)$ read as

$$
\begin{gathered}
\frac{d V_{i}}{d M}=\left(\tau_{H}-\tau_{L}\right)\left[\sum_{h \in H} U_{i h}^{x}-\left(n_{i}-h^{*}\right) \sum_{h=1}^{n_{i}} U_{i h}^{z}\right]=0 \\
\frac{d V_{i}}{d \tau_{L}}=\sum_{h \in L} U_{i h}^{x}\left[-\beta_{i h}\left(f_{i}-k_{i} f_{i}^{\prime}\right)\right]+\sum_{h \in H} U_{i h}^{x}[-M]+\sum_{h=1}^{n_{i}} U_{i h}^{z}\left[b_{L}\left(f_{i}-k_{i} f_{i}^{\prime}\right)+M\left(n_{i}-h^{*}\right)\right]=0 \\
\frac{d V_{i}}{d \tau_{H}}=\sum_{h \in H} U_{i h}^{x}\left[M-\beta_{i h}\left(f_{i}-k_{i} f_{i}^{\prime}\right)\right]+\sum_{h=1}^{n_{i}} U_{i h}^{z}\left[b_{H}\left(f_{i}-k_{i} f_{i}^{\prime}\right)-M\left(n_{i}-h^{*}\right)\right]=0 \\
\frac{d V_{i}}{d t_{i}}=\sum_{h \in L} U_{i h}^{x}\left[\alpha_{i h} \bar{k}_{i} \frac{\partial \rho}{\partial t_{i}}-\beta_{i h}\left(1-\tau_{L}\right) k_{i} f_{i}^{\prime \prime} \frac{\partial k_{i}}{\partial t_{i}}\right]+\sum_{h \in H} U_{i h}^{x}\left[\alpha_{i h} \bar{k}_{i} \frac{\partial \rho}{\partial t_{i}}-\beta_{i h}\left(1-\tau_{H}\right) k_{i} f_{i}^{\prime \prime} \frac{\partial k_{i}}{\partial t_{i}}\right] \\
+\sum_{h=1}^{n_{i}} U_{i h}^{z}\left[k_{i} f_{i}^{\prime}+\left(t_{i}\left(f_{i}^{\prime}+k_{i} f_{i}^{\prime \prime}\right)-\left(\tau_{L} b_{L}+\tau_{H} b_{H}\right) k_{i} f_{i}^{\prime \prime}\right) \frac{\partial k_{i}}{\partial t_{i}}\right]=0 .
\end{gathered}
$$

Using (23), $d V_{i} / d \tau_{L}$ in (24) and $d V_{i} / d \tau_{H}$ in (25) reduce to

$$
\begin{gathered}
\frac{d V_{i}}{d \tau_{L}}=\left(f_{i}-k_{i} f_{i}^{\prime}\right)\left[b_{L} \sum_{h=1}^{n_{i}} U_{i h}^{z}-\sum_{h \in L} U_{i h}^{x} \beta_{i h}\right]=0, \\
\frac{d V_{i}}{d \tau_{H}}=\left(f_{i}-k_{i} f_{i}^{\prime}\right)\left[b_{H} \sum_{h=1}^{n_{i}} U_{i h}^{z}-\sum_{h \in H} U_{i h}^{x} \beta_{i h}\right]>0,
\end{gathered}
$$

leading to a corner solution and $\tau_{H}=1 .{ }^{26}$ The inequality follows because $\sum_{h=1}^{n_{i}} U_{i h}^{z}=\sum_{h \in H} U_{i h}^{x} /\left(n_{i}-\right.$ $h^{*}$ ) from $(23)$ and hence

$$
b_{H} \sum_{h=1}^{n_{i}} U_{i h}^{z}-\sum_{h \in H} U_{i h}^{x} \beta_{i h}=\frac{b_{H}}{n_{i}-h^{*}} \sum_{h \in H} U_{i h}^{x}-\sum_{h \in H} U_{i h}^{x} \beta_{i h}=\sum_{h \in H} U_{i h}^{x}\left(\frac{b_{H}}{n_{i}-h^{*}}-\beta_{i h}\right)>0,
$$

given that the average of $\beta_{i h}$ in $H$ equals $b_{H} /\left(n_{i}-h^{*}\right)$ and that $\beta_{i h}$ increases in income while $U_{i h}^{x}$ decreases in income. Using (23), (27) and $\tau_{H}=1, d V_{i} / d t_{i}$ at $t_{i}=0$ in (26) becomes

$$
\begin{gathered}
\left.\frac{d V_{i}}{d t_{i}}\right|_{\left(t_{i}=0\right)}=\sum_{h \in L} U_{i h}^{x}\left[\alpha_{i h} \bar{k}_{i} \frac{\partial \rho}{\partial t_{i}}-\beta_{i h}\left(1-\tau_{L}\right) k_{i} f_{i}^{\prime \prime} \frac{\partial k_{i}}{\partial t_{i}}\right]+\sum_{h \in H} U_{i h}^{x}\left[\alpha_{i h} \bar{k}_{i} \frac{\partial \rho}{\partial t_{i}}-\beta_{i h}\left(1-\tau_{H}\right) k_{i} f_{i}^{\prime \prime} \frac{\partial k_{i}}{\partial t_{i}}\right] \\
\left.+\sum_{h=1}^{n_{i}} U_{i h}^{z}\left[k_{i} f_{i}^{\prime}-\left(\tau_{L} b_{L}+\tau_{H} b_{H}\right) k_{i} f_{i}^{\prime \prime}\right) \frac{\partial k_{i}}{\partial t_{i}}\right] \\
=\sum_{h \in L} U_{i h}^{x}\left[\alpha_{i h} \bar{k}_{i} \frac{\partial \rho}{\partial t_{i}}-\beta_{i h}\left(1-\tau_{L}\right) k_{i} f_{i}^{\prime \prime} \frac{\partial k_{i}}{\partial t_{i}}\right]+\sum_{h \in H} U_{i h}^{x} \alpha_{i h} \bar{k}_{i} \frac{\partial \rho}{\partial t_{i}}
\end{gathered}
$$

\footnotetext{
${ }^{26}$ If both $\tau_{L}$ and $\tau_{H}$ are chosen to satisfy (24) and (25) as equalities, then it can be shown that $d V_{i} / d M=\left(\tau_{H}-\right.$ $\left.\tau_{L}\right)\left[\sum_{h \in H} U_{i h}^{x}-\left(n_{i}-h^{*}\right) \sum_{h=1}^{n_{i}} U_{i h}^{z}\right]<0$ in (23), leading to a corner solution and $M=0$. This means that a single labor tax is optimal, defeating the purpose of a progressive tax.
} 


$$
\begin{gathered}
\left.+\sum_{h=1}^{n_{i}} U_{i h}^{z}\left[k_{i} f_{i}^{\prime}-\left(\tau_{L} b_{L}+b_{H}\right) k_{i} f_{i}^{\prime \prime}\right) \frac{\partial k_{i}}{\partial t_{i}}\right] \\
=\sum_{h \in L} U_{i h}^{x} \alpha_{i h} \bar{k}_{i} \frac{\partial \rho}{\partial t_{i}}+\sum_{h \in H} U_{i h}^{x} \alpha_{i h} \bar{k}_{i} \frac{\partial \rho}{\partial t_{i}}+\sum_{h=1}^{n_{i}} U_{i h}^{z}\left[k_{i} f_{i}^{\prime}-\left(b_{L}+b_{H}\right) k_{i} f_{i}^{\prime \prime} \frac{\partial k_{i}}{\partial t_{i}}\right] \\
=\sum_{h=1}^{n_{i}} U_{i h}^{x} \alpha_{i h} \bar{k}_{i} \frac{\partial \rho}{\partial t_{i}}+\sum_{h=1}^{n_{i}} U_{i h}^{z}\left[k_{i} f_{i}^{\prime}-k_{i} f_{i}^{\prime \prime} \frac{\partial k_{i}}{\partial t_{i}}\right] \\
=-\frac{k f_{i}^{\prime}}{D f_{i}^{\prime \prime}} \sum_{h=1}^{n_{i}} U_{i h}^{x} \alpha_{i h}+\frac{k f_{i}^{\prime}}{D f_{i}^{\prime \prime}} \sum_{h=1}^{n_{i}} U_{i h}^{z} \\
>\frac{k f_{i}^{\prime}}{D f_{i}^{\prime \prime}} \sum_{h=1}^{n_{i}} U_{i h}^{x}\left(\beta_{i h}-\alpha_{i h}\right)=\frac{k f_{i}^{\prime}}{D f_{i}^{\prime \prime}} \sum_{h=1}^{n_{i}} U_{i h}^{x}\left[-\delta_{i h}\right] .
\end{gathered}
$$

The first equality comes from $t_{i}=0$, and the second one uses $\tau_{H}=1$. The third equality follows from (27), and the next one uses $b_{L}+b_{H}=\sum_{h=1}^{n_{i}} \beta_{i h}=1$. The inequality follows because $b_{L}+b_{H}=\sum_{h=1}^{n_{i}} \beta_{i h}=1$, and because the sum of (27) and (28) leads to $\sum_{h=1}^{n_{i}} U_{i h}^{z}>\sum_{h=1}^{n_{i}} U_{i h}^{x} \beta_{i h}$. 


\section{References}

Banerjee A, Newman A (1993) Occupational choice and the process of development. Journal of Political Economy 101: 274-298.

Bayindir-Upmann T, Ziad A (2005) Existence of equilibria in a basic tax-competition model. Regional Science and Urban Economics 35: 1-22.

Borck R (2003) Tax competition and the choice of tax structure in a majority voting model. Journal of Urban Economics 54: 173-180.

Braulke M, Corneo G (2004) Capital taxation may survive in open economies. Annals of Economics and Finance 5: 237-244.

Brueckner J (2000) A Tiebout/tax-competition model. Journal of Public Economics 77: 285-306.

Bucovetsky S (1991) Assymetric tax competition. Journal of Urban Economics 30: 167-181.

Bucovetsky S, Wilson J (1991) Tax competition with two tax instruments. Regional Science and Urban Economics 21: 333-350.

Burbidge J, Cuff K, Leach J (2006) Tax competition with heterogeneous firms. Journal of Public Economics 90: 533-549.

Card D, Krueger A (1992) Does school quality matter? returns to education and the characteristics of public schools in the United States. Journal of Political Economy 100: 1-40.

Davies J, Shorrocks A, Sandstrom S, Wolff E (2007) The world distribution of household wealth. Center for Global, International and Regional Studies, University of California, Santa Cruz.

Diaz-Gimenez V, Quadrini V, Rios-Rull J (1997) Dimensions of inequality: facts on the U.S. distributions of earnings, income, and wealth. Quarterly Review (Federal Reserve Bank of Minneapolis) 21: 3-21.

Eaton J, Rosen H (1980a) Taxation, human capital, and uncertainty. American Economic Review 70: 705-715.

Eaton J, Rosen H (1980b) Labor supply, uncertainty, and efficient taxation. Journal of Public Economics 14: 365-374.

Fuest C, Huber B (2001) Labor and capital income taxation, fiscal competition, and the distribution of wealth. Journal of Public Economics 79: 71-91.

Galor O, Zeira J (1993) Income distribution and macroeconomics. Review of Economic Studies 60: $35-52$.

Goodman A, Johnson P, Webb S (1997) Inequality in the UK. Oxford University Press, Oxford.

Green G, Coder J, Ryscavage P (1990) International comparisons of earnings inequality for men 
in the 1980's. Luxembourg Income Study Working Paper Series, No. 58.

Grossman G, Helpman E (1994) Protection for sale. American Economic Review, 84: 833-850.

Haufler A (2001) Taxation in a global economy. Cambridge University Press, Cambridge.

Huber B (1997) Optimal income taxes and capital controls in small open economies. International Tax and Public Finance 4: 724.

Huber B (1999) Tax competition and tax coordination in an optimum income tax model. Journal of Public Economics 71: 441-458.

Huizinga H, Nielsen S (1997) Capital income and profit taxation with foreign ownership of firms. Journal of International Economics 42: 149-165.

Kessler A, Lulfelsmann C, Myers G (2002) Redistribution, fiscal competition, and the politics of economic integration. Review of Economic Studies 69: 899-923.

Koskela E, Schöb R (2005) Optimal capital taxation in economies with unionized and competitive labour markets. Oxford Economic Papers 57: 717-731.

Laussel D, Le Breton M (1998) Existence of Nash equilibria in fiscal competition models. Regional Science and Urban Economics 28: 283-296.

Lee K (2004) Taxation of mobile factors as insurance under uncertainty. Scandinavian Journal of Economics 106: 253271.

Loury G (1981) Intergenerational transfers and the distribution of earnings. Econometrica 49: 843-867.

Meltzer A, Richard S (1981) A rational theory of the size of government. Journal of Political Economy 89: 914-927.

Murnane R, Willett J, Levy F (1995) The growing importance of cognitive skills in wage determination. Review of Economics and Statistics 77: 251-266.

Ogawa H, Sato Y, Tamai T (2006) A note on unemployment and capital tax competition. Journal of Urban Economics 60: 350-356.

Organization for Economic Cooperation and Development (1998) Harmful tax competition: An emerging global issue. OECD, Paris.

Organization for Economic Cooperation and Development (2000) Towards global tax co-operation: Progress in identifying and eliminating harmful tax practices. OECD, Paris.

Persson T, Tabellini G (1992) The politics of 1992: fiscal policy and European integration. Review of Economic Studies 59: 689-701. 
Razin A, Sadka E (1991) Efficient investment incentives in the presence of capital flight. Journal of International Economics 31: 171181.

Richter W, Schneider K (2001) Taxing mobile capital with labor market imperfections. International Tax and Public Finance 8: 245-262.

Sörensen P (2004) International tax coordination: regionalism versus globalism. Journal of Public Economics 88: 1187-1214.

Vives X (2001) Oligopoly pricing: old ideas and new tools. MIT Press, Cambridge.

Wildasin D (1989) Interjurisdictional capital mobility: Fiscal externality and a corrective subsidy. Journal of Urban Economics 25: 193-212.

Wilson J (1991) Tax competition with interregional differences in factor endowments. Regional Science and Urban Economics 21: 423-452.

Wilson J, Wildasin D (2004) Capital tax competition: bane or boon. Journal of Public Economics 88: 1065-1091.

Zodrow G, Mieszkowski P (1986) Pigou, Tiebout property taxation, and the underprovision of local public goods. Journal of Urban Economics 19: 356-370. 